\title{
Optimal Conjunctive Use of Surface and Groundwater with Recharge and Return Flows: Dynamic and Spatial Patterns
}

\author{
by Sittidaj Pongkijvorasin \\ Department of Economics, University of Hawaii at Manoa \\ and James Roumasset ${ }^{1}$ \\ Department of Economics, University of Hawaii at Manoa \\ Working Paper No. 07-4 \\ March 5, 2007
}

\begin{abstract}
This paper derives the efficiency price patterns for a comprehensive spatial and dynamic model of conjunctive water use incorporating conveyance losses, canal return flows, and groundwater recharge. The first-best shadow price of surface water is composed of a charge for water that flows into the farm and differential credits for water that flows to other uses. The shadow prices can be used as the basis of water pricing schemes or for exchange rates to facilitate water trading. We show that farmers near the headworks use irrigation water in the optimal program, and only farmers more distant from the headworks extract groundwater. We also illustrate the possibility of reswitching in the sequence of resource use. It may be efficient for some farms to switch from one source to another and then switch back again, e.g. groundwater to surface water to groundwater.
\end{abstract}

JEL Classification: Q15, Q25, Q28

Keywords: water management, conjunctive use, irrigation, return flows, conveyance loss, consumptive use, sequence of resource use

Corresponding Author: James Roumasset, Department of Economics, University of Hawaii at Manoa, 2424 Maile Way, Honolulu, HI 96822. Phone: (808) 956-7496. Fax: (808) 956-4347 <jimr@hawaii.edu>

\footnotetext{
${ }^{1}$ We thank Kimberly Burnett, Alberto Garrido, Nori Tarui and participants in the AAEA session on New Frontiers in Water Resource Economics, ASSA Annual Meeting, Chicago, 2007, for helpful comments and suggestions.
} 


\section{Introduction}

Water scarcity and the environmental impact of water use is a growing topic of concern. Improving efficiency in irrigation water allocation, in terms of both scarcity and environmental impact, has drawn considerable attention from many economists and planners. Traditional studies usually model water allocation assuming that the users are independent. However, many early water resource economists pointed out the interdependency in water users (Hartman and Seastone 1970, Johnson, Gisser, and Werner 1981, and O’mara 1984). Considering the external impacts of water use on other farms, equating the marginal product of consumptive use is not necessarily an optimal outcome.

Water rights and water transfer are widely recommended instruments used to promote efficiency of water allocation (see for example, Easter, Rosegrant, and Dinar (1999)). But inasmuch as water transactions may result in water being transferred/transformed over space, time, and form, administrative review processes have been deemed a necessary oversight mechanism. These procedures, however, represent substantial transaction costs and tend to inhibit actual water transfers and robust water markets (Howe 1998). This calls for a system for determining efficiency prices over space, time, and form. By announcing exchange rates based on efficiency prices, the governing authority can streamline the review processes and expand trading.

This paper derives the efficiency price patterns for a comprehensive spatial and dynamic model of conjunctive water use that incorporates externalities from water use. Two externality forms will be emphasized in the model. The first one involves canal return flow, a positive externality. The second form concerns the interdependence between surface and groundwater. O’mara (1984) discusses the policies and incentive structures necessary to 
achieve efficiency when surface and groundwater are used jointly. The efficiency condition equalizes the discounted marginal products of surface water (reckoned at the headworks) and groundwater across space and time. Recently, Chakravorty and Umetsu (2003) constructed a spatial irrigation model of conjunctive use of surface and groundwater including conveyance losses. In a static framework, they find that it is optimal for upstream farmers to use canal water, while downstream farmers pump groundwater.

In this paper, the efficiency prices of surface and groundwater and their changes over space and time are discussed. We show that the main result of Chakravorty and Umetsu (2003), regarding the boundary between surface and groundwater usage, is preserved. We also show how the boundary changes in the dynamic framework and that the price of water exhibits a discontinuity at the boundary. The groundwater price increases over time, but the surface water price changes ambiguously. The surface water boundary moves further away from the headworks when the scarcity rent of groundwater increases but can move in either direction when it decreases. Four possible patterns of water use are presented. Some farms switch from groundwater to surface water, while other farms may switch from ground to surface water and back to groundwater again. Compared to Gaudet, Monreaux, and Salant (2001), reswitching in the sequence of resource use can occur even without setup costs in this setting.

The model is presented in the following section. Results and policy implications over space and time are the subjects of the subsequent sections. Conclusions are provided at the end of the paper. 


\section{The Model}

Consider a simplified model of an irrigation project. Water is supplied from a point source (also called headworks) into a canal. There are $n$ farms located along the canal. The distance from the headworks to each farm is denoted by $y_{i}(y=0$ represents the headworks, and $y$ increases away from it). Let $x_{i}$ be the water received by farmer $i$ ( $i=1$ designates the nearest farm to the headworks, while $n$th farm is the most distant one). Each farmer can divert water from the canal and uses it as an input for farm production.

There are conveyance losses (e.g. via seepage, percolation, and evaporation) in water transportation. Assume that $s_{i}$ is the percentage of water sent that is actually received by the ith farm. The conveyance loss depends on the distance from the headworks to each farm, $s_{i}=s\left(y_{i}\right)$, where $0 \leq s(y) \leq 1, s(0)=1$, and $s^{\prime}(y)<0$. Receiving $x_{i}$ units of water requires that $Q_{s i}=\frac{x_{i}}{s\left(y_{i}\right)}$ units be sent from the headworks. Assume that $\mu$ percent of conveyance loss percolates to the groundwater aquifer. The remaining conveyance losses evaporate during transportation and cannot be used elsewhere.

In addition to surface water, farmers can use groundwater for production. ${ }^{2}$ Denote $g_{i}$ as the amount of groundwater used by farm $i$. The marginal cost of extracting groundwater depends on the head level, $c_{g}(h) \geq 0$, where $c^{\prime}{ }_{g}(h)<0$ and $c^{\prime \prime}{ }_{g}(h) \geq 0$. There is also natural leakage from the groundwater aquifer (see for example Krulce, Roumasset, and Wilson 1997). Leakage is assumed to be a positive, increasing, and convex function in head level, $l(h) \geq 0, l^{\prime}(h)>0$, and $l^{\prime \prime}(h)>0$. The state of the aquifer can be explained by:

\footnotetext{
${ }^{2}$ Surface and groundwater are assumed to have identical qualities for farm production.
} 
$\dot{h}=a\left[R-l(h)-\sum_{i=1}^{n} g_{i}+\beta \sum_{i=1}^{n}\left(x_{i}+g_{i}\right)+\mu \sum_{i=1}^{n} \frac{1-s\left(y_{i}\right)}{s\left(y_{i}\right)} x_{i}\right]$

where $a$ is a conversion parameter that converts the aquifer's volume to height.

Assume that with one unit of received water, $k$ proportion is used for farm production (called consumptive use or evapotranspiration). $\beta$ percent of on-farm water use recharges to the underground aquifer. The rest, $(1-k-\beta)$, is canal return flow and is available for downstream users. ${ }^{3}$ In this paper, we use the term "received water" for water inflow at farm $\left(x_{i}\right)$, "net received water" for the net water received (received water - return flow), i.e., $(k+\beta) x_{i}$, and "consumptive use" or "evapotranspiration” for the water used in farm production $\left(k x_{i}\right)$. The corresponding schematic is shown in figure 1.

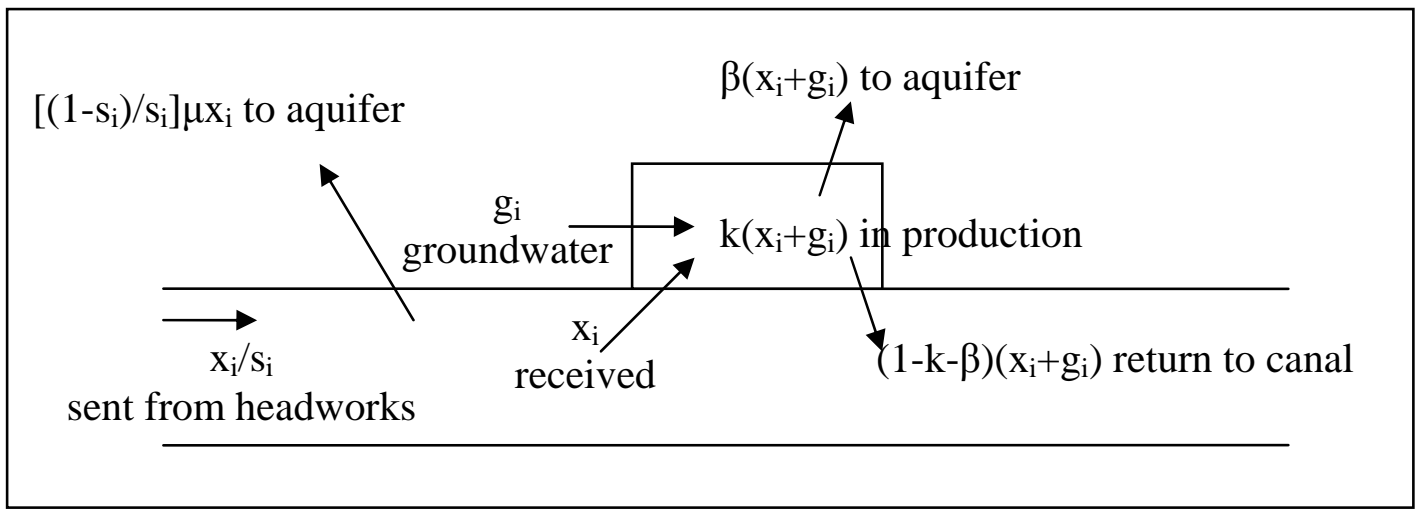

\section{Figure 1. Water flow schematic}

Inasmuch as the return flow to the canal will be available for use by the downstream farmer, the total amount of water sent from the headwork, $Z$, is not simply equal to the sum of sent water over all farms. The amount of water sent to farm i, $Q_{s i}$, is equal to:

\footnotetext{
${ }^{3}$ The amount of canal return flow also depends on on-farm technology, which is exogenously determined in this model. For farms located beyond the irrigation boundary, it is assumed that this drained return flow cannot be used by other farmers.
} 
$Q_{s i}=\frac{x_{i}}{s\left(y_{i}\right)}-(1-k-\beta) \frac{\left(x_{i-1}+g_{i-1}\right)}{s\left(y_{i-1}\right)}$

The second term on the right-hand side is the canal return flow coming from the closer farm. The total water sent from the headworks can be expressed as:

$Z=\sum_{i=1}^{m} Q_{s i}=\sum_{i=1}^{n} \frac{x_{i}}{s\left(y_{i}\right)}-(1-k-\beta) \sum_{i=1}^{m-1} \frac{\left(x_{i}+g_{i}\right)}{s\left(y_{i}\right)}$

where $m$ is the last farm using the surface water.

The social planner chooses the amounts of surface water and groundwater used in order to maximize social welfare, i.e.:

$\max _{x_{i}, g_{i}} \int_{t=0}^{\infty}\left[\sum_{i=1}^{n} \int_{0}^{k x_{i}+k g_{i}} p f_{i}^{\prime}\left(q_{i}\right) d q-c Z-\sum_{i=1}^{n} c_{g}(h) g_{i}\right] e^{-r t} d t$

s.t. $\quad Z=\sum_{i=1}^{m} Q_{s i}=\sum_{i=1}^{n} \frac{x_{i}}{s\left(y_{i}\right)}-(1-k-\beta) \sum_{i=1}^{m-1} \frac{\left(x_{i}+g_{i}\right)}{s\left(y_{i}\right)}$

and $\quad \dot{h}=a\left[R-l(h)-\sum_{i=1}^{n} g_{i}+\beta \sum_{i=1}^{n}\left(x_{i}+g_{i}\right)+\mu \sum_{i=1}^{n} \frac{1-s\left(y_{i}\right)}{s\left(y_{i}\right)} x_{i}\right]$

where $p$ is the price of the farm product, $f($.$) is the production function, and q_{i}$ is the total consumptive use, which is equal to $k\left(x_{i}+g_{i}\right)$. The production function is assumed to have traditional properties, i.e. $f^{\prime}(q)>0, f^{\prime}{ }^{\prime}(q)<0 .{ }^{4}$ The cost of sending surface water is given by the constant per unit cost, $c$. The discount rate is given by r. Denoting $\lambda$ as the shadow price of groundwater in terms of the head level, the first order conditions are as follows:

\footnotetext{
${ }^{4}$ The production function depends on on-farm technology. For example, with the same amount of consumptive use, drip irrigation will result in more output than furrow irrigation. This paper assumes that on-farm technology is exogenously determined.
} 


$$
\begin{aligned}
\frac{\partial \tilde{H}}{\partial x_{i}} & =k p f_{i}^{\prime}\left(k x_{i}+k g_{i}\right)-\frac{c}{s\left(y_{i}\right)}+\frac{c(1-k-\beta)}{s\left(y_{i}\right)}+\lambda a \beta+\lambda a \mu \frac{\left(1-s\left(y_{i}\right)\right)}{s\left(y_{i}\right)} \leq 0 \\
& =k p f_{i}^{\prime}\left(k x_{i}+k g_{i}\right)-\frac{c}{s\left(y_{i}\right)}+\lambda a \beta+\lambda a \mu \frac{\left(1-s\left(y_{i}\right)\right)}{s\left(y_{i}\right)} \leq 0 \quad\left(=0, \text { if } x_{i}>0\right) ; i=1, \ldots, m-1
\end{aligned}
$$

$$
\begin{aligned}
\frac{\partial \tilde{H}}{\partial g_{i}} & =k p f_{i}^{\prime}\left(k x_{i}+k g_{i}\right)-c_{g}(h)+\frac{c(1-k-\beta)}{s\left(y_{i}\right)}-\lambda a+\lambda a \beta \leq 0 & \left(=0, \text { if } g_{i}>0\right) ; i=1, \ldots, m-1 \\
& =k p f_{i}^{\prime}\left(k x_{i}+k g_{i}\right)-c_{g}(h)-\lambda a+\lambda a \beta \leq 0 & \left(=0, \text { if } g_{i}>0\right) ; i=m, \ldots, n
\end{aligned}
$$

$$
-\frac{\partial \tilde{H}}{\partial h}=c_{g}{ }^{\prime}(h) \sum_{i=1}^{n} g_{i}+\lambda a l^{\prime}(h)=\dot{\lambda}-r \lambda
$$

Comparing equations (4) and (5), surface water will be used when the marginal cost of water sent, net of its value added to the aquifer, is less than the full marginal cost of groundwater

(extraction and user cost), i.e., $\frac{c}{s\left(y_{i}\right)}-\lambda a \mu \frac{\left(1-s\left(y_{i}\right)\right)}{s\left(y_{i}\right)}<c_{g}(h)+\lambda a$, and vice versa.

\section{Efficiency prices over space}

For the farmer using surface water, the efficiency price for surface water received at each location (except the last one) can be derived from equation (4):

$$
p_{x}\left(y_{i}\right)=\frac{c}{s\left(y_{i}\right)}-\frac{c(1-k-\beta)}{s\left(y_{i}\right)}-\lambda a \beta-\lambda a \mu \frac{\left(1-s\left(y_{i}\right)\right)}{s\left(y_{i}\right)}=k p f_{i}^{\prime}\left(k x_{i}+k g_{i}\right) \ldots \text { (7) }
$$

Equation (7) shows the optimal unit price of received water for a farmer at distance $y$. The water authority can implement efficient water allocation by charging $p_{x}$ per unit of received water or $p_{x} / k$ per unit of consumptive use. Charging the marginal cost of sending water for consumptive use is not optimal, unless there is no groundwater recharge.The efficiency pricing in equation (7) can be implemented by charging the full cost for the 
received water $\left(\frac{c}{s\left(y_{i}\right)}\right.$ per unit) and giving differential credits for canal return flow $\left(\frac{c}{s\left(y_{i}\right)}\right.$ per unit) and percolation to the aquifer ( $\lambda a$ per unit). For the last farm using surface water, it is optimal to charge for received water and credit back only the parts flowing to the aquifer. The canal return flow will not be credited for the last farm, as the water will not be used by other farms. Under the condition that the cost of sending surface water is higher than the value of its conveyance loss, i.e. $c \geq \lambda a \mu$ (otherwise surface water's highest value is in its conversion to groundwater, not direct use), the optimal price for surface water is increasing with distance, $p_{x}{ }^{\prime}(y)>0$.

For the groundwater use within the surface water boundary, the efficiency price is determined by:

$p_{g}\left(y_{i}\right)=c_{g}(h)+\lambda a-\frac{(1-k-\beta) c}{s\left(y_{i}\right)}-\lambda a \beta$

The optimal policy for groundwater is to charge the extraction cost and user cost while giving credit for the canal return flow, and groundwater recharge from on-farm water use. However, groundwater users outside the surface water boundary do not receive the credit for the canal return flow, i.e.

$p_{g}\left(y_{i}\right)=c_{g}(h)+\lambda a-\lambda a \beta$

Unlike surface water, within the surface irrigation area, the efficiency price for groundwater is decreasing with distance. The marginal costs of groundwater are all equal outside the surface water area.

Considering a general case where surface and groundwater are used conjunctively, there exists a critical distance $\left(0<y_{c}<y_{n}\right)$ where both prices are equal. The condition specifying $y_{c}$ can be expressed as: 


$$
\frac{c}{s\left(y_{c}\right)}-\lambda a \mu \frac{\left(1-s\left(y_{c}\right)\right)}{s\left(y_{c}\right)}=c_{g}(h)+\lambda a
$$

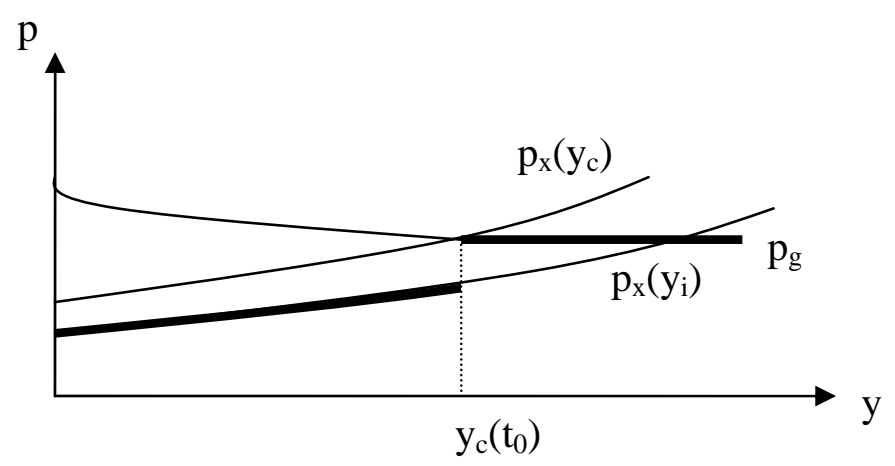

\section{Figure 2. Efficiency price vs. distance from headworks $(t=0)$}

Figure 2 shows the critical distance where farms start using groundwater. The $p_{x}\left(y_{i}\right)$ curve shows the increasing price path of surface water. ${ }^{5}$ The $p_{x}\left(y_{c}\right)$ curve shows the price of surface water in the case that the farm is the last farm receiving irrigated surface water. Farms located between the headworks and $y_{c}$ will use only surface water as the price is cheaper than the cost of groundwater. At $y_{c}$, a farmer can use either surface water or groundwater. Farms located beyond $y_{c}$, on the other hand, will use only groundwater, as the cost is cheaper than the price of surface water. The marginal cost of water used by farmers in different locations is represented by the bold lines in figure 2. This verifies that the main results of Chakravorty and Umetsu (2003) hold in each period in a dynamic setting. Note however that, in this case, the unit price of water paid by the farmer is not continuous over the distance. At the critical distance, the price jumps to the cost of groundwater. This happens because the model takes into account the return flow to the canal.

\footnotetext{
${ }^{5}$ Convexity or concavity of the price depends on the conveyance efficiency function.
} 


\section{Dynamic changes in efficiency prices of surface and groundwater}

From equation (7) and (9), the difference between the growth of surface water price and the groundwater price can be expressed by:

$$
\dot{p}_{x}\left(y_{i}\right)-\dot{p}_{g}\left(y_{i}\right)=-c_{g}{ }^{\prime}(h) \dot{h}-\dot{\lambda} a-\dot{\lambda} a \mu \frac{\left(1-s\left(y_{i}\right)\right)}{s\left(y_{i}\right)}
$$

Assuming that the initial head level is higher than the steady state, then the head level decreases over time, $\dot{h}<0$. If the scarcity rent of groundwater is increasing, equation (11) is unambiguously negative. In other words, the price of groundwater is rising faster than that of surface water (the price of surface water is decreasing in this case). Some farms initially using groundwater will switch to surface water when its price becomes cheaper. This implies that the surface water boundary expands over time. The total amount of surface water use increases, while total groundwater extraction decreases.

For the range of time wherein scarcity rent is decreasing, equation (11) has an ambiguous sign. If at $\mathrm{y}_{c}$, the surface water price rises slower than the groundwater price (i.e. $\left.-c_{g}{ }^{\prime}(h) \dot{h}-\dot{\lambda} a-\dot{\lambda} a \mu \frac{\left(1-s\left(y_{c}\right)\right)}{s\left(y_{c}\right)}<0\right)$, the surface water price will be less than the groundwater price in the following period. This implies that the irrigation boundary expands. There can be some farms switching from using groundwater to surface water. On the other hand, if at $y_{c}$, the groundwater price rises slower than the price of surface water (i.e.

$\left.-c_{g}{ }^{\prime}(h) \dot{h}-\dot{\lambda} a-\dot{\lambda} a \mu \frac{\left(1-s\left(y_{c}\right)\right)}{s\left(y_{c}\right)}>0\right)$, groundwater will become cheaper in the next period.

This implies that the surface water area shrinks. Some farms will switch from using surface water to groundwater. 
In practice, scarcity rent may change non-monotonically over time; for example, the scarcity rent of groundwater extraction with a backstop resource (e.g. seawater desalination) increases at the beginning, and then decreases later on (Krulce, Roumasset, Wilson 1997). As a result, it is optimal for some farms to make more than one switch (i.e. groundwater to surface water to groundwater). Figure 3 shows the possible cases. Farms located near the headworks will always use surface water, while some distant farms will always use groundwater. Some farms make one switch from groundwater to surface water after some periods. It is also possible for reswitching to occur in the order of water use. Some farms initially use groundwater, but, as scarcity rent increases, they switch to surface water. Then when scarcity rent falls, they switch back to groundwater. Even though there are no set-up costs in this model (as in Gaudet, Monreaux, and Salant (2001)), reswitching in water use is possible due to the groundwater recharge.

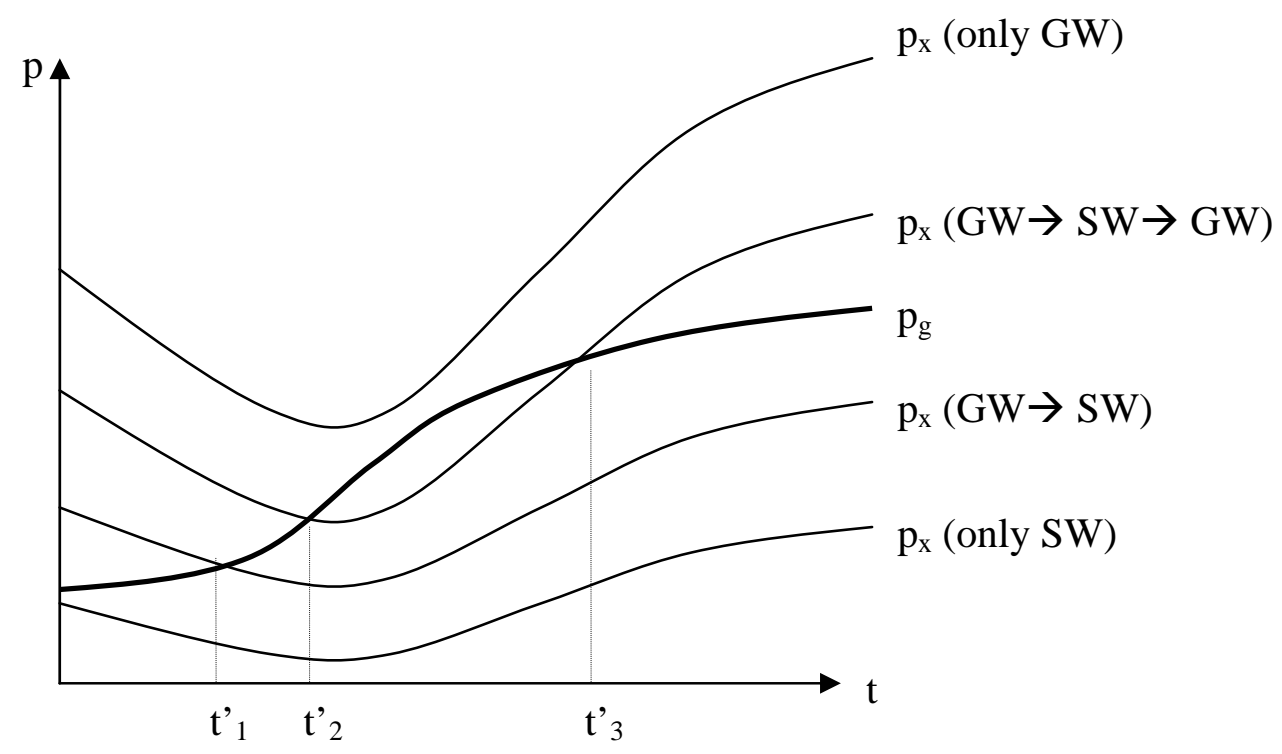

Figure 3. Price paths of surface and groundwater when scarcity rent is increasing and decreasing over time. Four possible resource orderings are illustrated, including switching from ground to surface water and reswitching back again. 


\section{Conclusions}

In order to effect optimal water resource use through decentralized institutions, one requires the shadow prices of irrigation water, taking into account conveyance losses, canal return flows, and groundwater recharge. The first-best shadow price of surface water is composed of a charge for water that flows into the farm and differential credits for water that flows to other uses. We find that charging the marginal cost of sending water for consumptive use is sub-optimal and that a discontinuity in efficiency pricing occurs at the (endogenous) tail of the surface irrigation system. Conveyance losses result in an increasing optimal price of surface water over the distance. Farmers near the headworks use irrigation water, and only farmers more distant from the headworks extract groundwater in the optimal solution.

Over time, when groundwater scarcity rent is increasing, some farms that previously used groundwater may switch to use surface water. However, when groundwater scarcity rent is decreasing, the switch in water use can occur in both directions: from groundwater to surface water or from surface water to groundwater. With rising and falling scarcity rent (e.g. renewable resource extraction with a backstop), it is possible that some farms switch from one source to another and then switch back again (e.g. groundwater to surface water to groundwater). Reswitching in water use is possible because the model accounts for groundwater recharge. The specialization pattern of water use over space still prevails.

Due to our focus on first-best patterns of allocation and efficiency prices, informational and political economy issues need further consideration prior to implementation of the pricing principles proposed. Straight marginal cost pricing, for example, may be burdensome and perceived to be inequitable. Some distant farmers may 
have to pay more for less water. Some of these problems may be solvable through block pricing. Optimal policy requires charging the optimal price for only the marginal unit of water use. Alternatively, farmers can be granted water entitlements that they can marginally sell or supplement at the appropriate marginal cost.

In the presence of imperfect information about water productivity, mechanisms can be designed to reveal differential productivities. To the extent that such mechanisms are costly and/or incompletely reveal productivity information, schemes that approximate the proposed solution but which save on administrative costs are natural candidates for further exploration.

One useful extension to the framework presented here would be to add a downstream user to the framework. This could be used to model the use of shadow prices to effect water transfers from agriculture to urban uses. The differential shadow pricing method can also be extended to differences in water quality. Conceptually, farmers should be charged the shadow price of pollution, which varies spatially due to quantities of water used and chemical inputs at each location. Quality differences may be especially important for the case of water transfers. For example, it may be efficient to transfer relatively more groundwater to urban uses than surface water. Finally, one can extend the model to distinguish between optimal use patterns and equilibrium departures from optimality due to non-cooperative behavior, regulations, and enforcement costs. 


\section{References}

Chakravorty, U., and C. Umetsu. "Basinwide water management: a spatial model.” Journal of Environmental Economics and Management 45, 2003: 1-23.

Easter, K. W., M. W. Rosegrant, and A. Dinar. "Formal and Informal Markets for Water: Institutions, Performance, and Constraints.” World Bank Research Observer 14(1), Feb 1999: 99-116

Gaudet, G., M. Moreaux, and S.W. Salant. “Intertemporal Depletion of Resource Sites by Spatially Distributed Users.” The American Economic Review 91(4), Sep 2001: 1149-1159.

Hartman, L. M., and D. Seastone. Water Transfer, Economic Efficiency and Alternative Institutions. Baltimore: The Johns Hopkins University Press, 1970.

Howe, Charles W. “Water Markets in Colorado: Past Performance and Needed Changes.” In Easter K.W., M.W. Rosegrant, and A. Dinar (Eds.), Markets for water: Potential and performance. Boston: Kluwer Academic Publishers, 1998.

Johnson, R. N., M. Gisser, and M. Werner. “The Definition of a Surface Water Right and Transferability.” Journal of Law and Economics 26, 1981: 273-288.

Krulce, D. L., J.A. Roumasset, and T. Wilson. “Optimal Management of a Renewable and Replaceable Resource: The case of Coastal Groundwater.” American Journal of Agricultural Economics 79, Nov 1997: 1218-1228.

O’mara, G. T.. Issues in the Efficient Use of Surface and Groundwater in Irrigation. Washington DC: World Bank Staff Work, Paper no. 707, 1984. 